\title{
Effect of off-pump coronary artery bypass surgery on clinical, angiographic, neurocognitive, and quality of life outcomes: randomised controlled trial
}

\author{
Sharif Al-Ruzzeh, Shane George, Mahmoud Bustami, Jo Wray, Charles Ilsley, Thanos Athanasiou, Mohamed Amrani
}

\begin{abstract}
Objective To compare the clinical, angiographic, neurocognitive, and quality of life outcomes of off-pump coronary artery bypass surgery with conventional coronary artery bypass grafting surgery using cardiopulmonary bypass. Design Randomised controlled clinical trial.

Setting Tertiary cardiothoracic centre in Middlesex, England. Participants 168 patients (27 women) requiring primary isolated coronary artery bypass grafting surgery. Interventions Patients were randomised to conventional coronary artery bypass grafting surgery using cardiopulmonary bypass $(\mathrm{n}=84)$ or off-pump coronary artery bypass surgery $(n=84)$, carried out by one surgeon. Angiographic examination was carried out at three months postoperatively. Neurocognitive tests were carried out at baseline and at six weeks and six months postoperatively.

Main outcome measures Clinical outcome, graft patency at three months, neurocognitive function at six weeks and six months, and health related quality of life.

Results Graft patency was evaluated by angiography in 151 $(89.9 \%)$ patients and was similar between the cardiopulmonary bypass and off-pump groups (risk difference - 1\%, 95\% confidence interval $-5 \%$ to $4 \%$ ), with the off-pump group considered the treatment group. Patients in the off-pump group required fewer blood transfusions ( 1.7 units $v 1.0$ unit, $\mathrm{P}=0.02)$, shorter duration of mechanical ventilation (7.7 hours $v 3.9$ hours, $\mathrm{P}=0.03$ ), and shorter hospital stay (10.8 days $v 8.9$ days). Scores for neurocognitive function showed a significant difference in three memory subtests at six weeks and two memory subtests at six months in favour of the off-pump group.

Conclusions Patients who underwent off-pump coronary artery bypass surgery showed similar patency of grafts, better clinical outcome, shorter hospital stay, and better neurocognitive function than patients who underwent conventional coronary artery bypass grafting surgery using cardiopulmonary bypass.
\end{abstract}

\section{Introduction}

Coronary artery bypass grafting surgery has classically been carried out through the median sternotomy approach using cardiopulmonary bypass with cardiac arrest. This method provides the most ideal operative field for a motionless and bloodless heart surface, with easy access to epicardial coronary arteries. Efforts were made to move to off-pump coronary artery bypass surgery because of well documented side effects of cardiopulmonary bypass. Concerns were raised, however, about the rate of graft patency and lack of uniformity in technical approach. Conflicting data from randomised controlled trials raised further controversies but did not tackle all the relevant aspects. A recent meta-analysis of randomised and observational studies concluded that the findings of randomised trials contradicted each other to some extent and, aside from atrial fibrillation, the statistically significant reductions in short term mortality and morbidity shown by observational studies could not be proved. ${ }^{1}$ These discrepancies could be attributed to differing patient selection or study methods and, more importantly, reliance on different surrogate end points.

In our centre we have used a systematic approach in adopting off-pump coronary artery bypass surgery. We shifted to the non-selective use of the off-pump technique for all patients requiring primary isolated coronary artery bypass grafting surgery and found similar clinical outcome with a low conversion rate. ${ }^{2}$ We further analysed the initial experience with off-pump coronary artery bypass surgery in the United Kingdom and showed a reduction in risk stratified morbidity and mortality at a multicentre level. ${ }^{3}$ We also retrospectively analysed our data on specific groups of patients, including elderly patients, ${ }^{4}$ high risk patients, ${ }^{5}$ and patients with ischaemic left ventricular dysfunction ${ }^{6}$ or sequential grafts. ${ }^{7}$ Having gone through the learning curve, we aimed, in this study, to compare the two techniques for clinical outcome, graft patency (evaluated by angiography), neurocognitive function, and health related quality of life.

\section{Patients and methods}

We prospectively randomised 168 patients to conventional coronary artery bypass grafting surgery using cardiopulmonary bypass $(n=84)$ or to off-pump coronary artery bypass grafting surgery ( $\mathrm{n}=84$; figure). Randomisation used minimisation in an Excel program to balance the groups for the following factors: sex, left ventricular function, diabetes, and age. Assignment to either on-pump or off-pump, was done on the operation day with the surgeon being informed immediately before the procedure.

Blinding of the surgeon was not possible. All other staff were blinded: medical, paramedical, and nursing staff on the intensive therapy unit, the ward staff, and the study staff, including the cardiologist who carried out the angiography and commented on the angiograms and the psychologist who carried out the tests for neurocognitive function. Patients and their relatives were also 
blinded to the procedure. Clinical decisions on patient management on the intensive therapy unit and the ward were taken by blinded staff and were based on local protocols and guidelines, including decisions on extubation, blood transfusion, and discharge. To ensure complete blinding the type of procedure was not stated in the clinical notes or in any correspondence. If a clinical necessity for disclosing information arose then the nominated principal investigator (SA) was contacted and given the name and study number of the patient. This was required on only one occasion, for a patient who died at six days postoperatively in the off-pump group.

We excluded patients with severe left ventricular dysfunction (ejection fraction $<30 \%$ ), renal failure (serum creatinine $\geq 180$ $\mu \mathrm{mol}$ or active renal replacement therapy), those who needed concomitant cardiac surgery using cardiopulmonary bypass, those who needed emergency surgery after angiographic intervention, those who were unable to effectively communicate in English (a requirement for neurocognitive testing), those who did not accept to undergo angiography after surgery, and those who had isolated single vessel disease requiring single coronary bypass.

The primary end points were angiographic graft patency (equivalence trial) and neurocognitive function (efficacy trial).
The secondary end points were clinical outcome and health related quality of life.

Perioperative myocardial infarction was indicated by the presence of new $\mathrm{Q}$ waves on the electrocardiogram, a creatine kinase-muscle brain concentration $>50 \mathrm{ng} / \mathrm{ml}$ with electrocardiographic changes, or a creatine kinase-muscle brain concentration $>70 \mathrm{ng} / \mathrm{ml}$ without electrocardiographic changes. Atrial fibrillation was confirmed by 12 lead electrocardiography. A neurological deficit was considered to be a cerebrovascular accident if focal neurological signs and symptoms persisted for more than 24 hours and this was confirmed by computed tomography; but was considered a transient ischaemic attack if the focal neurological signs and symptoms lasted less than 24 hours. Renal impairment was diagnosed clinically on the basis of laboratory results or by the requirement of haemofiltration. Blood transfusion was given during hospital stay if the haemoglobin level was less than $80 \mathrm{~g} / \mathrm{l}$. Blood products, including fresh frozen plasma and platelets, were given as indicated by thromboelastography if the patient was bleeding on arrival at the intensive therapy unit.

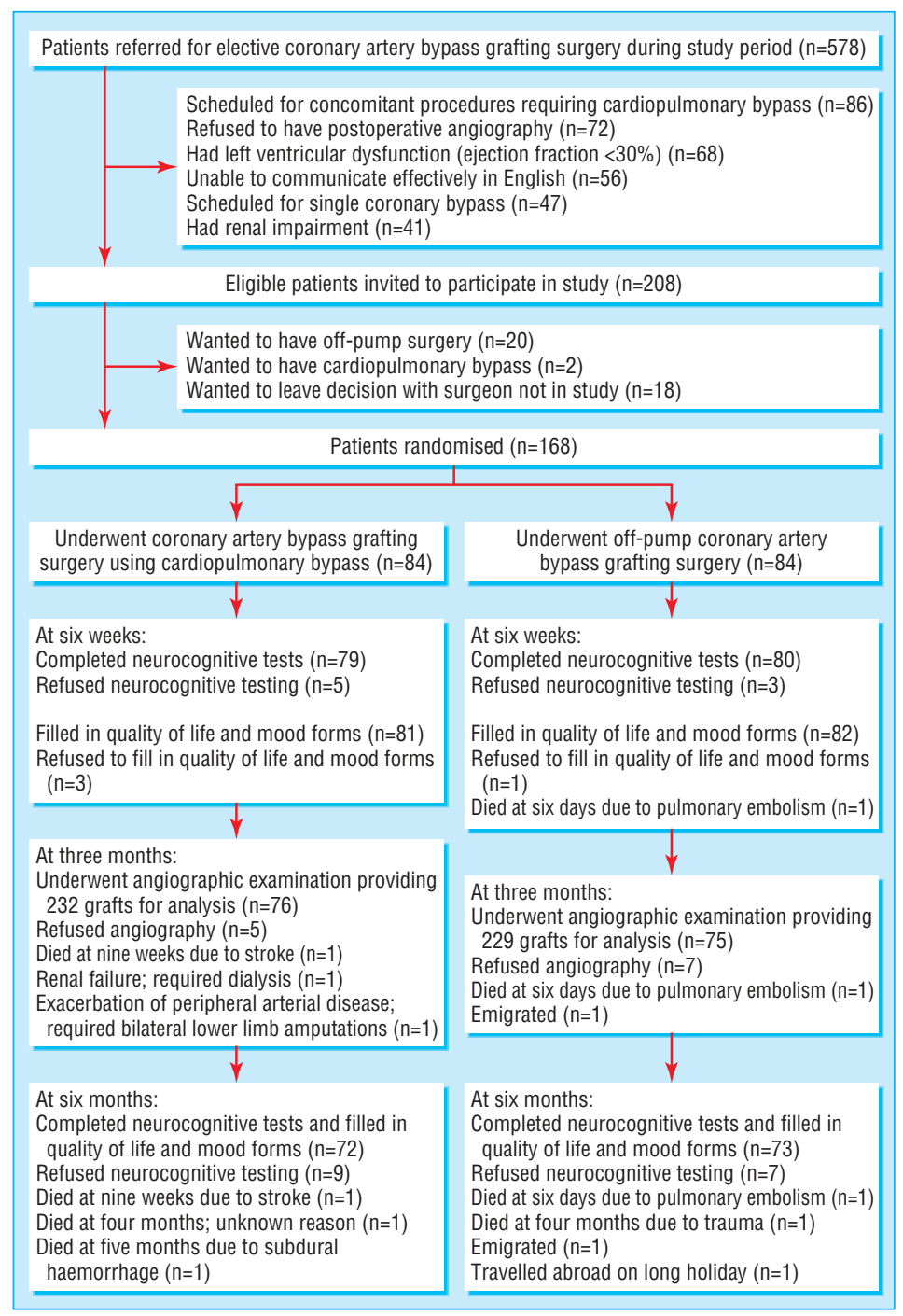

Flow of patients through trial 


\section{Surgical technique}

One surgeon (MA) carried out the operations in both arms of the study. Anaesthesia was induced using propofol $1-2 \mathrm{mg} / \mathrm{kg}$, pancuronium $0.1 \mathrm{mg} / \mathrm{kg}$, and fentanyl 8-15 $\mu \mathrm{g} / \mathrm{kg}$ and maintained by air and oxygen and propofol $2-3 \mathrm{mg} / \mathrm{kg} / \mathrm{hour}$. Normothermia was maintained with warm intravenous fluids, a heating mattress, a humidified airway, and a warm operating theatre.

The heart was exposed using a standard midline sternotomy incision. After the internal thoracic arteries had been harvested the pericardium was opened using an inverted T-shaped incision. To minimise haemodynamic compromise the right pleural space was opened to create a space for the rotated and vertically positioned heart.

Either or both of the internal thoracic arteries was harvested as a wide pedicle including artery, vein, muscle, fascia, and adipose tissue and was sprayed with diluted papaverine solution (50 mg/20 ml normal saline). The left radial artery was used preferentially regardless of hand dominance, as this allows simultaneous harvesting of the left internal thoracic artery. In our hospital we use a flushing solution of $50 \mathrm{mg}$ phenoxybenzamine, $20 \mathrm{ml}$ of blood, and 2000 units of heparin.

\section{Off-pump technique}

The heart was stabilised using the suction-irrigation tissue stabilisation system Octopus 3 (Medtronic, Minneapolis, USA). A deep pericardial retraction suture helped position the heart for grafting. The technique is described in detail elsewhere. ${ }^{7}$

Anticoagulation was achieved with $150 \mathrm{U} / \mathrm{kg}$ of heparin. If required, heparin was supplemented to maintain the activated clotting time above 250 seconds and was reversed by protamine at the end of the procedure. Blood pressure was continually optimised during the procedure, and the mean arterial pressure was maintained above $50 \mathrm{~mm} \mathrm{Hg}$ by repositioning the heart and by intravenous fluids or selective use of vasoconstrictors, or both.

\section{Cardiopulmonary bypass technique}

Cardiopulmonary bypass was instituted with a single right atrial two stage cannula and an ascending aorta perfusion cannula. Standard bypass management included membrane oxygenators, arterial line filters, systemic hypothermia down to $32^{\circ} \mathrm{C}$, and non-pulsatile flow of $2.4 \mathrm{l} / \mathrm{min} / \mathrm{m}^{2}$, with a mean arterial pressure greater than $50 \mathrm{~mm} \mathrm{Hg}$. The myocardium was protected by using intermittent antegrade cold blood cardioplegia (4:1 blood to crystalloid ratio). Anticoagulation was achieved using 300 $\mathrm{U} / \mathrm{kg}$ of heparin. If required, heparin was supplemented to maintain the activated clotting time above 480 seconds and was reversed by protamine at the end of the procedure.

\footnotetext{
Angiography

Participants were booked for angiography three months after surgery. Each of the grafts was engaged and two orthogonal views of each were obtained along with two orthogonal views of each of the coronary arteries. If an aortocoronary graft could not be identified, aortography was carried out. Subclavian arteriography was carried out if an internal thoracic artery graft could not be identified. The angiographic patency of the grafts was graded as either patent (graft open all the way through) or occluded (graft completely blocked even if a patent stump was seen at the proximal end using subclavian arteriography or aortography). Angiograms were obtained and commented on by one cardiologist (MB), who was blinded to the study arm.
}

\section{Neurocognitive function, mood state, and health related} quality of life

The neurocognitive tests were planned in accordance with the statement of consensus of assessment of neurobehavioral outcomes after cardiac surgery. ${ }^{8}$ We used a battery composed of 11 memory subtests of the Wechsler memory scale (third edition) and two intelligence subtests of the Wechsler adult intelligence scale (third edition) to assess the neurocognitive performance of the two groups at three time points (day before surgery, six weeks postoperatively, six months postoperatively). The memory subsets comprised logical memory 1 (total and thematic), logical memory 2 (total and thematic), faces, family pictures, verbal paired associates, letter-number sequencing, digit span-forward, digit span-backward, mental control, trail A, and trail B. The intelligence subtests comprised vocabulary and block design.

The consensus also recommended an assessment of mood state as this is believed to influence neurocognitive performance. The hospital anxiety and depression scale was therefore administered with the neurocognitive tests. This scale consists of 14 items and was developed to assess anxiety and depression in an outpatients' setting irrespective of physical symptoms. ${ }^{9}$ Seven items measure anxiety and seven measure depression. Each item is scored from 0 to 3 , with total scores ranging from 0 to 21 for the anxiety and depression subscales. Higher scores indicate greater anxiety and depression.

We assessed health related quality of life at the same time as the neurocognitive tests using the World Health Organization quality of life questionnaire. This questionnaire assesses 100 items in the six domains of physical health, psychological health, level of independence, social relationships, environment, and spirituality. Each item is scored from 0 to $5 .^{10}$

\section{Statistical analysis}

We designed our trial with adequate power $(80 \%$; alpha level of $0.05)$ to detect an absolute difference in angiographic patency as small as $5 \%$ between the two groups in either direction. We used the Blackwelder's method ${ }^{11}$ for the power calculation, and baseline or expected patency rate was considered as high as $96 \%$. This rate has been reported when arterial grafts were commonly used,$^{12}$ which has been the routine practice in our institution. Evidence from the literature suggested that a smaller number of patients would be required to show a difference in neurocognitive function between the two groups. ${ }^{13}$

We expressed continuous variables as means and standard deviations. To test for the correlation between these variables we used Pearson's correlation test. We compared categorical variables using Fisher's exact test or the $\chi^{2}$ test, and we compared group means using Student's $t$ test or the Mann Whitney U test.

To analyse scores on the hospital anxiety and depression scale and the World Health Organization quality of life questionnaire, we carried out repeated measures analysis. Analysis of covariance was used to analyse the neurocognitive test scores. Analysis of covariance has a high statistical power and adjusts each participant's follow-up measurement according to his or her baseline measurement. ${ }^{14}$ It also prevents regression to the mean, which can make natural variation in repeated data seem like a real change. ${ }^{15}$

We considered differences significant when $P$ values were less than or equal to 0.05 . We analysed data using SPSS version 12.0 for Windows and Intercooled Stata version 8.0 for Windows. 
Table 1 Preoperative characteristics of patients assigned to cardiopulmonary bypass or off-pump coronary artery bypass. Values are numbers (percentages) unless stated otherwise

\begin{tabular}{lcc} 
Variable & $\begin{array}{c}\text { Cardiopulmonary } \\
\text { bypass group ( } \mathbf{n}=\mathbf{8 4})\end{array}$ & $\begin{array}{c}\text { Off-pump coronary } \\
\text { artery bypass group } \\
(\mathbf{n}=\mathbf{8 4})\end{array}$ \\
\hline Mean (SD) age (years) & $63.1(9.6)$ & $63.1(11)$ \\
\hline Mean (SD) body mass index & $27.5(4.0)$ & $28.1(4.5)$ \\
\hline Women & $13(16)$ & $14(17)$ \\
\hline Current smoker & $35(42)$ & $37(44)$ \\
\hline $\begin{array}{l}\text { Recent myocardial infarction (within 30 } \\
\text { days) }\end{array}$ & $12(14)$ & $13(16)$ \\
\hline New York Heart Association grade III or IV & $16(19)$ & $18(21)$ \\
\hline Canadian Cardiac Society grade III or IV & $36(43)$ & $38(45)$ \\
\hline Left ventricular function: & $65(77)$ & $66(79)$ \\
\hline Ejection fraction $>50 \%$ & $19(23)$ & $18(21)$ \\
\hline Ejection fraction 30\%-49\% & $18(21)$ & $20(24)$ \\
\hline $\begin{array}{l}\text { Diabetes (tablet controlled and insulin } \\
\text { dependant) }\end{array}$ & $67(80)$ & $69(82)$ \\
\hline Hypercholesterolaemia & $46(55)$ & $52(62)$ \\
\hline Hypertension & $7(8)$ & $5(6)$ \\
\hline Chronic obstructive airway disease & $6(7)$ & $7(8)$ \\
\hline Peripheral arterial disease & & \\
\hline
\end{tabular}

\section{Results}

Baseline characteristics were similar between patients assigned to conventional coronary artery bypass grafting surgery and those assigned to off-pump coronary artery bypass grafting surgery (table 1). No cross over occurred between the two groups. Table 2 shows the clinical outcome data, including morbidity and mortality. One patient allocated to off-pump surgery died in hospital six days after surgery due to pulmonary embolism (confirmed by postmortem examination). In-hospital mortality was equivalent to mortality at six weeks (42 days); no further patients died between the two time points.

Patients in the cardiopulmonary bypass group required significantly longer mechanical ventilation than patients in the off-pump group (7.7 hours $v 3.9$ hours, $\mathrm{P}=0.03)$, significantly more blood transfusions (1.7 units $v 1.0$ unit, $\mathrm{P}=0.02)$, and longer stay in hospital (10.8 days $v 8.9$ days, $\mathrm{P}=0.03)$.

\section{Angiographic outcome}

Overall $151(89.9 \%)$ patients underwent angiography three months postoperatively: 75 in the off-pump group and 76 in the cardiopulmonary bypass group, providing 461 grafts for analysis (table 3). The blocked grafts are listed in brackets in table 3 after the total number of grafts to each particular target coronary artery of the heart.

In total, 17 of $232(7.3 \%)$ grafts were blocked in the cardiopulmonary bypass group, and 18 of $229(7.9 \%)$ grafts were blocked in the off-pump group. Thus, cardiopulmonary bypass group had an angiographic patency of $92.7 \%$ compared with $92.1 \%$ for the off-pump group (odds ratio $1.08,95 \%$ confidence interval 0.54 to 2.15 ; risk difference $-1 \%,-5 \%$ to $4 \%$ ), with the off-pump group considered the treatment group.

\section{Neurocognitive function, mood state, and health related quality of life}

At six weeks 159 patients completed the neurocognitive test (79 in the cardiopulmonary bypass group and 80 in the off-pump group) and at six months 145 patients completed the neurocognitive test (72 in the cardiopulmonary bypass group and 73 in the off-pump group; table 4). The off-pump group performed significantly better in three memory subtests at six weeks (verbal paired associates, $\mathrm{P}<0.001$; letter-number sequencing,
Table 2 Postoperative morbidity and mortality in patients assigned to cardiopulmonary bypass or off-pump coronary artery bypass. Values are numbers (percentages) unless stated otherwise

\begin{tabular}{|c|c|c|c|}
\hline Variable & $\begin{array}{l}\text { Cardiopulmonary } \\
\text { bypass group } \\
(\mathrm{n}=84)\end{array}$ & $\begin{array}{l}\text { Off-pump coronary } \\
\text { artery bypass } \\
\text { group }(\mathrm{n}=84)\end{array}$ & $P$ value \\
\hline Perioperative myocardial infarction & $1(1)$ & 1 (1) & 0.48 \\
\hline Reoperation for bleeding & $2(2)$ & $3(4)$ & 1 \\
\hline Atrial fibrillation & $22(26)$ & $28(33)$ & 0.4 \\
\hline \multicolumn{4}{|l|}{ Pulmonary complications: } \\
\hline Re-intubation & $7(8)$ & $3(4)$ & 0.2 \\
\hline Tracheostomy & $4(5)$ & $1(1)$ & 0.2 \\
\hline Pneumonia & $1(1)$ & 0 & 0.5 \\
\hline Pneumothorax & $7(8)$ & $3(3.6)$ & 0.2 \\
\hline Pleural effusion & $8(10)$ & $5(6)$ & 0.6 \\
\hline $\begin{array}{l}\text { Mean (SD) ventilation duration } \\
\text { (hours) }\end{array}$ & 7.7 (19.6) & $3.9(6.2)$ & 0.03 \\
\hline Transient ischaemic attack & $1(1)$ & 0 & 1 \\
\hline Cerebrovascular event & $1(1)$ & $2(2)$ & 1 \\
\hline \multicolumn{4}{|l|}{ Renal complications: } \\
\hline Renal impairment & $14(17)$ & $8(10)$ & 0.15 \\
\hline Haemofiltration & $5(6)$ & $2(2)$ & 0.27 \\
\hline $\begin{array}{l}\text { Readmission to intensive therapy } \\
\text { unit }\end{array}$ & $6(7)$ & $1(1)$ & 0.12 \\
\hline $\begin{array}{l}\text { Mean (SD) stay in intensive therapy } \\
\text { unit (hours) }\end{array}$ & $142(800)$ & $35.8(51.7)$ & 0.081 \\
\hline Mean (SD) stay in hospital (days) & $10.8(7.17)$ & $8.9(4.7)$ & 0.03 \\
\hline $\begin{array}{l}\text { Mean (SD) chest drainage in first } 24 \\
\text { hours }(\mathrm{ml})\end{array}$ & $981.1(618)$ & $937.6(695.9)$ & 0.34 \\
\hline $\begin{array}{l}\text { Mean (SD) blood transfusion (red } \\
\text { blood cell units) }\end{array}$ & $1.7(1.9)$ & $1(1.9)$ & 0.02 \\
\hline $\begin{array}{l}\text { Mean (SD) blood product } \\
\text { transfusion (fresh frozen plasma } \\
\text { and platelet units) }\end{array}$ & $0.54(1.1)$ & $0.45(1.2)$ & 0.6 \\
\hline In-hospital mortality & 0 & $1(1)$ & 1 \\
\hline
\end{tabular}

$\mathrm{P}=0.001$; and trail $\mathrm{A}, \mathrm{P}=0.01)$ and in two memory subtests at six months (letter-number sequencing, $\mathrm{P}<0.001$; and trail $\mathrm{A}$, $\mathrm{P}<0.001)$.

Repeated measures analysis of scores on the hospital anxiety and depression scale at baseline, six weeks, and six months showed no significant difference in mood state (table 5). The repeated measures analysis of the World Health Organization quality of life scores at the same time points showed significant improvement in only social relationships $(\mathrm{P}=0.04$; table 5). Although a trend was seen for better scores in the off-pump group in the other five domains, this was not significant.

\section{Discussion}

Patients who underwent off-pump coronary artery bypass grafting surgery had similar graft patency rates to patients who underwent conventional coronary artery bypass grafting surgery using cardiopulmonary bypass. Patients in the off-pump group, however, needed a shorter stay in hospital, shorter duration of mechanical ventilation in the intensive therapy unit, and fewer blood transfusions, and had better preservation of neurocognitive function at six weeks and six months.

The finding of a significantly shorter period of mechanical ventilation in the off-pump group concurs with some randomised trials ${ }^{16-18}$ but not all. ${ }^{19-22}$ This could be due to several reasons, including statistical methods used for evaluation, the variability in local practice and protocols between centres and teams, and even differences in the type of patients randomised. Despite this contradiction, recent evidence suggests that this difference in ventilation requirements could be more related to myocardial damage, ${ }^{23}$ that is, some degree of pump failure, than 
Table 3 Analysis of distal anastomoses studied by angiography in patients assigned cardiopulmonary bypass or off-pump coronary artery bypass (the numbers of blocked grafts are listed in brackets after the total number of grafts to each particular target coronary artery of the heart)

\begin{tabular}{|c|c|c|c|c|c|}
\hline Variable & Left internal thoracic artery & Right internal thoracic artery & Radial artery & Saphenous vein & Total \\
\hline \multicolumn{6}{|l|}{ Cardiopulmonary bypass: } \\
\hline Left anterior descending artery & $46(1)$ & 20 & 1 & 1 & $68(1)$ \\
\hline Diagonal or intermediate arteries & 5 & 2 & $8(1)$ & 10 & $25(1)$ \\
\hline Circumflex artery, obtuse marginal artery & $31(2)$ & 9 & 13 & $24(5)$ & $77(7)$ \\
\hline $\begin{array}{l}\text { Right coronary artery, posterior descending artery, } \\
\text { left ventricular branch of right coronary artery }\end{array}$ & 1 & 0 & $28(5)$ & $33(3)$ & $62(8)$ \\
\hline Total & $83(3)$ & 31 & $50(6)$ & $68(8)$ & $232(17)$ \\
\hline \multicolumn{6}{|l|}{ Off-pump coronary artery bypass: } \\
\hline Left anterior descending artery & $45(1)$ & 28 & 2 & 0 & $75(1)$ \\
\hline Diagonal or intermediate arteries & 3 & 0 & $12(1)$ & 7 & $22(1)$ \\
\hline Circumflex artery, obtuse marginal artery & 27 & $9(1)$ & $13(2)$ & $21(4)$ & $70(7)$ \\
\hline $\begin{array}{l}\text { Right coronary artery, posterior descending artery, } \\
\text { left ventricular branch of right coronary artery }\end{array}$ & 1 & 0 & $28(2)$ & $33(7)$ & $62(9)$ \\
\hline Total & 76 (1) & 37 (1) & $55(5)$ & 61 (11) & $229(18)$ \\
\hline
\end{tabular}

to lung damage caused by cardiopulmonary bypass. ${ }^{24}$ The difference in ventilation time was not associated with a difference in stay in the intensive therapy unit. This could be because clinical decisions on discharge were made once or twice daily.

The off-pump group required significantly fewer blood transfusions than the cardiopulmonary bypass group. This was not correlated with blood loss through postoperative chest drainage in the first 24 hours as previously reported ${ }^{25}$ but could be explained by dilution of the patient's blood by the priming solution. ${ }^{17}$ The difference in requirements for blood transfusion between the two groups was not uniform in previous randomised trials, with some reporting a significant difference ${ }^{16-19}$ and others none. ${ }^{20-22}$ We showed that hospital stay was significantly shorter in patients in the off-pump group.

Using coronary angiography, the standard method for qualitative and quantitative assessment of bypass grafts, we showed that patients in the off-pump group had similar patency rates to patients in the cardiopulmonary bypass group. A discrepancy has been found in reported patency rates after off-pump surgery. Graft patency rates at three years were shown by one study to be lower in patients undergoing off-pump surgery. Patency rates of $92 \%$ and 54\% for left internal thoracic artery and saphenous vein graft with cardiopulmonary bypass surgery compared with
$41 \%$ and $23 \%$, respectively, with off-pump surgery. ${ }^{26}$ These results were ascribed to the surgical technique, comprising occlusion of the coronary target proximal and distal to the anastomotic site using silicon rubber tapes and without adequate stabilisation. ${ }^{16}$ Another study showed a significantly lower patency rate for saphenous vein grafts $(47.1 \%)$ than for internal thoracic arteries $(95.7 \%)$ in patients followed-up for three years after offpump surgery. ${ }^{27}$ A significantly lower patency of saphenous vein grafts has also been shown both early and at one year after off-pump surgery, but comparable patency of arterial grafts between the off-pump group and cardiopulmonary bypass group. ${ }^{28}$ These blocked saphenous vein grafts were explained mainly by the increased procoagulant activity in the first 24 hours after off-pump surgery, which could contribute to the risk of venous thrombosis and blockage of aortocoronary grafts. ${ }^{29}$ Extending this to recently reported randomised trials, the discrepancy still exists: no difference in patency rates between the two groups (200 patients) at 30 days and one year, with operations carried out by one surgeon ${ }^{18}$; no difference at one year in $70(25 \%)$ patients in a multicentre trial $^{30}$; and a significant difference between the two groups (103 patients), with operations carried out by two surgeons. ${ }^{19}$ This was attributed to differences in experience of off-pump bypass surgery between

Table 4 Neurocognitive performance of patients at six weeks and six months after cardiopulmonary bypass or off-pump coronary artery bypass. Values are means (standard deviations) unless stated otherwise

\begin{tabular}{|c|c|c|c|c|c|c|c|c|}
\hline \multirow[b]{2}{*}{ Subtest } & \multicolumn{4}{|c|}{ Six weeks' assessment } & \multicolumn{4}{|c|}{ Six months' assessment } \\
\hline & $\begin{array}{l}\text { Cardiopulmonary } \\
\text { bypass group }\end{array}$ & $\begin{array}{l}\text { Off-pump coronary } \\
\text { artery bypass } \\
\text { group }\end{array}$ & $\begin{array}{l}\text { Mean difference }(95 \% \\
\text { CI) }\end{array}$ & $P$ value & $\begin{array}{c}\text { Cardiopulmonary } \\
\text { bypass group }\end{array}$ & $\begin{array}{c}\text { Off-pump } \\
\text { coronary artery } \\
\text { bypass group }\end{array}$ & $\begin{array}{l}\text { Mean difference }(95 \% \\
\text { CI) }\end{array}$ & $P$ value \\
\hline \multicolumn{9}{|l|}{ Logical memory 1 : } \\
\hline Total & $33.3(10.6)$ & $34.3(12.3)$ & $-2.1(-5$ to 0.6$)$ & 0.1 & $34.6(11)$ & $35.6(14.1)$ & $-2.5(-5.7$ to 0.8$)$ & 0.1 \\
\hline Thematic & $13(4)$ & $13.4(4.6)$ & $-1 \quad(-2.1$ to 0.2$)$ & 0.1 & $14(4.5)$ & $13.5(4.7)$ & $-0.2(-1.6$ to 1.1$)$ & 0.8 \\
\hline \multicolumn{9}{|l|}{ Logical memory 2: } \\
\hline Total & $19.3(8.3)$ & $20(9.5)$ & $-1.7(-3.7$ to 0.4$)$ & 0.1 & $20.2(9.2)$ & 18.9 (12) & 0.002 (-2.7 to 2.7$)$ & 1 \\
\hline Thematic & $7.7(3.1)$ & $7.7(3.8)$ & $-0.5(-1.5$ to 0.5$)$ & 0.3 & $8.2(3.6)$ & $7.2(4.6)$ & $0.4(-0.8$ to 1.5$)$ & 0.5 \\
\hline Faces & $69.5(9.2)$ & $68.7(13.4)$ & $-0.4(-3.2$ to 2.4$)$ & 0.8 & $66.9(18.9)$ & $64.7(22.7)$ & 0.9 (-5.7 to 7.6$)$ & 0.8 \\
\hline Family pictures & $60(22.8)$ & $63.9(28.8)$ & $-3.5(-8.7$ to 1.7$)$ & 0.2 & $57.6(27.2)$ & $53.9(31.5)$ & $3.8(-4.7$ to 10.6$)$ & 0.4 \\
\hline Verbal paired associates & $8.4(9.8)$ & $15.8(9.1)$ & $-7.1(-9.6$ to -4.6$)$ & $<0.001$ & $14.9(11.1)$ & $15.7(11)$ & $-1.6(-5$ to 1.8$)$ & 0.4 \\
\hline Letter-number sequencing & $6(3.1)$ & $7.9(3.6)$ & $-1.5(-2.4$ to -0.6$)$ & 0.001 & $4.8(3.3)$ & $7.34(3.4)$ & $-2.5(-3.4$ to -1.5$)$ & $<0.001$ \\
\hline Digit span-forward & $10(2.4)$ & $10.4(1.9)$ & $-0.5(-1.1$ to 0.1$)$ & 0.1 & $10.5(2.2)$ & $10.5(1.9)$ & $-0.2(-0.8$ to 0.4$)$ & 0.6 \\
\hline Digit span-backward & $5.7(2.3)$ & $5.9(2.4)$ & $-0.04 \quad(-0.6$ to 0.6$)$ & 1 & $5.7(2.3)$ & $5.8(2.5)$ & $-0.1(-0.7$ to 0.5$)$ & 0.7 \\
\hline Mental control & $26(6.2)$ & $27(6.1)$ & $-0.3(-1.7$ to 1.1$)$ & 0.7 & $26.5(6.4)$ & $26(7)$ & $0.5(-1.2$ to 2.2$)$ & 0.6 \\
\hline Trail A & 43.8 (14.3) & $37.8(17.7)$ & 5 (1.1 to 8.9$)$ & 0.01 & $40.2(12.8)$ & $32.3(11.9)$ & 7.9 (3.6 to 12.3$)$ & $<0.001$ \\
\hline Trail B & $115.4(41.6)$ & $111.4(46.6)$ & $5.6(-4.8$ to 16$)$ & 0.3 & $102.4(44)$ & $109.4(66)$ & $-1.4(-13.7$ to 10.8$)$ & 0.8 \\
\hline Vocabulary & $32.8(10)$ & $34.3(11.9)$ & $0.1(-1.6$ to 1.8$)$ & 0.9 & $33.8(10.7)$ & $33.4(11.5)$ & $1.1(-0.8$ to 3.1$)$ & 0.3 \\
\hline Block design & 35.1 (11.5) & 35.6 (13.4) & $-0.3(-2.4$ to 1.8$)$ & 0.8 & 36.6 (11.8) & 36.8 (14.7) & $-1.2(-3.5$ to 1.2$)$ & 0.3 \\
\hline
\end{tabular}


Table 5 Repeated measures analysis of scores on hospital anxiety and depression scale and World Health Organization quality of life questionnaire

\begin{tabular}{lcc} 
Variable & F ratio & P value \\
\hline Hospital anxiety and depression scale: & & \\
\hline Anxiety component & 0.54 & 0.47 \\
\hline Depression component & 3.7 & 0.06 \\
\hline WHO quality of life questionnaire: & & \\
\hline Physical health & 2.8 & 0.09 \\
\hline Psychological & 3.2 & 0.08 \\
\hline Level of independence & 3.5 & 0.06 \\
\hline Social relationships & 4.2 & 0.04 \\
\hline Environment & 3.3 & 0.07 \\
\hline Spirituality, religion, personal beliefs & 3 & 0.09 \\
\hline Overall & 3.2 & 0.08 \\
\hline
\end{tabular}

the centres before and during the trials and the conduits used. For example, in the last trial more radial artery grafts were used in the off-pump group and at the time of angiography $24 \%$ of them were blocked compared with no blockages in similar grafts in the cardiopulmonary bypass group. ${ }^{19}$

To minimise or eliminate bias from differences in learning curves, surgeons, centres, and conduits, we gained experience, before starting the trial, from non-selective use of the off-pump technique in more than 500 unselected patients, ${ }^{2}$ using different types of arterial and venous grafts. ${ }^{31}{ }^{32}$

We found that off-pump surgery was associated with better preservation of neurocognitive function at six weeks and six months after surgery. The difference between the two groups was statistically significant in three memory subtests at six weeks and two memory subtests at six months. This deterioration in neurocognitive function happened in the absence of any accompanying change in the mood state, which could have contributed to the difference in performance. ${ }^{8}$

Since the mid-1990s a fundamental change has occurred in the demographics of patients requiring cardiac surgery. Largely as a result of factors related to increasing age of this group, major neurological complications constituted a growing percentage of serious postoperative morbidity. ${ }^{33}$ Stroke occurs in $1-3 \%$ of patients undergoing cardiac surgery and is mainly due to embolisation by atheromatous debris during manipulation of the diseased aorta. ${ }^{34}$ However, cognitive impairment, which is predominantly caused by microembolisation of gaseous and particulate matter is a more common form of neuorological injury related to coronary artery bypass surgery but at the same time more difficult to assess or quantify than stroke. ${ }^{35}$ Others have measured the occurrence of microemboli during cardiac surgery using transcranial Doppler ultrasonography, when the microemboli produce a characteristic high intensity transcranial signal. ${ }^{36}$ The increase in water content of the brain caused by cardiopulmonary bypass has also been suggested as another major factor in the decline in neurocognitive function after coronary artery bypass graft surgery. ${ }^{37}$ Neurocognitive tests have been developed, refined, and validated and are reliable and sensitive detectors of any changes in neurocognitive performance after cardiac surgery. They have been used as an end point for the assessment of the neurological effects of perioperative factors, management of patients undergoing cardiopulmonary bypass, and new techniques such as off-pump coronary artery bypass surgery. For example, postoperative hyperthermia and atrial fibrillation were independently found to be associated with neurocognitive dysfunction. ${ }^{38}{ }^{39}$ Furthermore, the technical details for management of patients undergoing cardiopulmonary bypass surgery, such as temperature, whether hypothermic or normothermic, $\mathrm{pH}$, and even the rate of rewarming, have been evaluated for their effect on neurocognitive performance. ${ }^{40-42}$

A longitudinal assessment of neurocognitive function in patients after cardiopulmonary bypass surgery showed that the cognitive decline could still be present in $42 \%$ at five years after surgery. ${ }^{43}$ Recent randomised trials comparing the neurocognitive performance of patients after off-pump surgery or cardiopulmonary bypass surgery have reported contradictory results. One trial of 281 patients reported no difference in cognitive outcome at three and 12 months ${ }^{44}$ but in a separate report on 219 patients the authors still concluded that early cognitive decline at four days after surgery predicted cognitive outcome at three months more prominently in patients after cardiopulmonary bypass surgery. ${ }^{45}$ In contrast, two trials, recruiting fewer patients, reported significantly better neurocognitive performances in patients after off-pump surgery. ${ }^{13} 46$

The difference between those trials was attributed to differences in the statistical methods or tests of neurocognitive performance used. ${ }^{47}$ To overcome this problem, experts have recommended calculating score change from baseline and then using analysis of covariance to compare changes in mean scores between the group and a control group. ${ }^{48}$ The major disadvantages of the single case definitions, such as a decline of one standard deviation or $20 \%$ change, is that high performers at baseline will be more likely classified as having deteriorated, even in the absence of real change, because of regression to the mean. ${ }^{48}$ This concept has already been adopted and implemented in large multicentre trials. ${ }^{49}$

\section{Limitations of the study}

An important inherent limitation of our trial is the reliance on surrogate end points, such as graft patency and neurocognitive function, rather than patient outcomes such as myocardial infarction, stroke, and death. ${ }^{50}$ Carrying out a clinical randomised trial in one centre to assess such patient outcomes is, however, logistically challenging as it requires a large sample size or long patient follow-up, or both..$^{50}$

Another limitation of our trial is that the power calculation was based on a relatively high expected patency rate $(96 \%)$, which could have influenced the sample size required for this trial aimed to test equivalence rather than superiority. Despite the inherent weakness of this approach, ${ }^{11}$ we made every effort to minimise its effect. ${ }^{51}$

We thank Derek Robinson (Sussex University) for help with statistical planning.

Contributors: SA and CI were principal investigators. SG was responsible for anaesthetic management of the patients. MB carried out the angiography and commented on the angiograms. SA and JW carried out and analysed the neurocognitive tests. TA carried out the statistical analysis. MA was a principal investigator and carried out all the operations in the trial. Competing interests: None declared.

Ethical approval: This study was approved by the Royal Brompton and Harefield research ethics committee.

1 Wijeysundera D, Beattie S, Djaiani G, Rao V, Borger M, Karkouti K. Off-pump coronary artery surgery for reducing mortality and morbidity. Meta-analysis of randomized and observational studies. J Am Coll Cardiol 2005;46:872-82.

2 Anyanwu A, Al-Ruzzeh S, George S, Patel R, Yacoub M, Amrani M. Conversion to offpump coronary bypass without increased morbidity or change in practice. Ann Thorac Surg 2002;73:798-802.

3 Al-Ruzzeh S, Ambler G, Asimakopoulos G, Omar RZ, Hasan R, Fabri B, et al. Off-pump coronary artery bypass (OPCAB) surgery reduces risk-stratified morbidity and mortality: a United Kingdom multi-centre comparative analysis of early clinical outcome. $\mathrm{Cir}$ ity: a United Kingdom multi-ce
culation $2003 ; 108$ (suppl II): $1-8$.

4 Al-Ruzzeh S, George S, Yacoub M, Amrani M. The clinical outcome of off-pump coroAl-Ruzzeh S, George S, Yacoub M, Amrani M. The clinical outcome of off-pump coro-
nary artery bypass surgery in elderly patients. Eur J Cardiothorac Surg 2001;20:1152-6. 5 Al-Ruzzeh S, Nakamura K, Athanasiou T, Modine T, George S, Yacoub M, et al. Does off-pump coronary artery bypass (OPCAB) surgery improve the outcome in high-risk 
patients?: a comparative study of 1398 high-risk patients. Eur J Cardiothorac Surg 2003;23:50-5.

6 Al-Ruzzeh S, Athanasiou T, George S, Glenville BE, DeSouza AC, Pepper JR, et al. Is the use of cardiopulmonary bypass for multivessel coronary artery bypass surgery an independent predictor of operative mortality in patients with ischemic left ventricula dysfunction? Ann Thorac Surg 2003;76:444-51; discussion 451-2

7 Al-Ruzzeh S, George S, Bustami M, Nakamura K, Khan S, Yacoub M, et al. The early clinical and angiographic outcome of sequential coronary artery bypass grafting with the off-pump technique.J Thorac Cardiovasc Surg 2002;123:525-30.

8 Murkin J, Newman S, Stump D, Blumenthal J. Statement of consensus on assessment of neurobehavioral outcomes after cardiac surgery. Ann Thorac Surg 1995;59:1289-95.

9 Zigmond A, Snaith R. The hospital anxiety and depression scale. Acta Psychiatrica Scandinavica 1983;67:361-70.

10 The WHOQOL Group. The World Health Organization quality of life assessment (WHOQOL): development and general psychometric properties. Soc Sci Med $1998 ; 46: 1569-85$

11 Sample size for an equivalence study. www.ucalgary.ca/ patten/blackwelder.html (accessed 28 Mar 2006).

12 Calafiore A, Contini M, Vitolla G, Di Mauro M, Mazzei V, Teodori G, et al. Bilatera internal thoracic artery grafting: long-term clinical and angiographic results of in situ versus Y grafts.J Thorac Cardiovasc Surg 2000;120:990-6.

13 Zamvar V, Williams D, Hall J, Payne N, Cann C, Young K, et al. Assessment of neurocognitive impairment after off-pump and on-pump techniques for coronary artery bypass graft surgery: prospective randomised controlled trial. BMJ 2002:325:1268-71.

14 Twisk J. Applied longitudinal data analysis for epidemiology: a practical guide. Cambridge: Cambridge University Press, 2003.

15 Barnett A, van der Pols J, Dobson A. Regression to the mean: what it is and how to deal with it. Int J Epidemiol 2005;34:215-20.

16 Angelini G, Taylor F, Reeves B, Ascione R. Early and midterm outcome after off-pump and on-pump surgery in beating heart cardioplegic arrest studies (BHACAS 1 and 2): a pooled analysis of two randomised controlled trials. Lancet 2002;359:1194-9.

17 Van Dijk D, Nierich AP, Jansen EW, Nathoe HM, Suyker WJ, Diephuis JC, et al. Early outcome after off-pump versus on-pump coronary bypass surgery: results from a randomised study. Circulation 2001;104:1761-6.

18 Puskas J, Williams W, Duke P, Staple JR, Glas KE, Marshall JJ, et al. Off-pump coronary artery bypass grafting provides complete revascularization with reduced myocardial injury, transfusion requirements and length of stay: a prospective randomised injury, transfusion requirements and length of stay: a prospective randomised
comparison of two hundred unselected patients undergoing off-pump versus conventional coronary artery bypass grafting. J Thorac Cardiovasc Surg 2003;125:797-808.

19 Khan NE, De Souza A, Mister R, Flather M, Clague J, Davies S, et al. A randomised comparison of off-pump and on-pump multivessel coronary artery bypass surgery. $N$ Engl J Med 2004;350:21-8.

20 Legare JF, Buth KJ, King S, Wood J, Sullivan JA, Friesen CH, et al. Coronary bypass surgery performed off pump does not result in lower in-hospital morbidity than coronary artery bypass grafting performed on pump. Circulation 2004;109:887-92.

21 Straka Z, Widimsky P, Jirasek K, Stros P, Votava J, Vanek T, et al. Off-pump versus on-pump coronary surgery: final results from a prospective randomised study on-pump coronary surgery: final results fiom

22 Gerola L, Buffolo E, Jasbik W, Botelho B, Bosco J, Brasil LA, et al. Off-pump versus on-pump myocardial revascularization in low-risk patients with one or two vessel disease: perioperative results in a multicenter randomised controlled trial. Ann Thora Surg 2004;77:569-79.

23 Onorati F, De Feo M, Mastroroberto P, Cristodoro L, Pezzo F, Renzulli A, et al. Determinants and prognosis of myocardial damage after coronary artery bypass grafting. Ann Thorac Surg 2005;79:837-45.

24 Cox C, Ascione R, Cohen A, Davies I, Ryder I, Angelini G. Effect of cardiopulmonary bypass on pulmonary gas exchange: a prospective randomised study. Ann Thorac Surg 2000;69:140-5.

25 Ascione R, Williams S, Lloyd C, Sundaramoorthi T, Pitsis A, Angelini G. Reduced postoperative blood loss and transfusion requirement after beating heart coronary operations: a prospective randomised study.J Thorac Cardiovasc Surg 2001;121:689-96.

\section{What is already known on this topic}

Cardiopulmonary bypass is suggested to be a contributing factor to neurocognitive dysfunction after conventional coronary artery bypass grafting surgery

Concerns were raised about graft patency after off-pump coronary artery bypass grafting surgery, which is at least as safe as conventional coronary artery bypass grafting surgery for clinical outcome

\section{What this study adds}

Rates of graft patency are similar between coronary artery bypass grafting surgery using cardiopulmonary bypass and off-pump coronary artery bypass grafting surgery

Patients in the off-pump bypass group showed better preservation of neurocognitive function at six weeks and six months and better clinical outcomes
26 Gundry S, Romano M, Shattuck O, Razzouk A, Bailey L. Seven-year follow-up of coronary artery bypasses performed with and without cardiopulmonary bypass. $J$ Thorac Cardiovasc Surg 1998;115:1273-8.

27 Omeroglu S, Kirali K, Guler M, Toker M, Ipek G, Isik O, et al. Midterm angiographic assessment of coronary artery bypass grafting without cardiopulmonary bypass. Ann Thorac Surg 2000;70:844-50.

$28 \mathrm{Kim} \mathrm{K,} \mathrm{Lim} \mathrm{C,} \mathrm{Lee} \mathrm{C,} \mathrm{Chae} \mathrm{I,} \mathrm{Oh} \mathrm{B,} \mathrm{Lee} \mathrm{M,} \mathrm{et} \mathrm{al.} \mathrm{Off-pump} \mathrm{coronary} \mathrm{artery} \mathrm{bypass} \mathrm{may}$ decrease the patency of saphenous vein grafts. Ann Thorac Surg 2001;72:S1033-7.

29 Mariani M, Gu Y, Boonstra P, Grandjean J, Van Oeveren W, Ebels T. Procoagulant activity after off-pump coronary operation: is the current anticoagulation adequate? Ann Thorac Surg 1999;67:1370-5.

30 Nathoe H, van Dijk D, Jansen E, Suyker W, Diephuis J, van Boven W, et al. A comparison of on-pump and off-pump coronary bypass surgery in low-risk patients. $N$ Engl J (1)

31 Al-Ruzzeh S, George S, Bustami M, Nakamura K, Ilsley C, Amrani M. Early clinical and angiographic outcome of the pedicled right internal thoracic artery graft to the left anterior descending artery. Ann Thorac Surg 2002;73:1431-5.

32 Al-Ruzzeh S, Modine T, Athanasiou T, Mazrani W, Azeem F, Nakamura K, et al. Can the use of the radial artery be expanded to all patients with different surgical grafting techniques? J Card Surg 2005;20:1-7

33 McKhann G, Goldsborough M, Borowicz L Jr, Mellits ED, Brookmeyer R, Quaskey S, et al. Predictors of stroke risk in coronary artery bypass patients. Ann Thorac Surg 1997;63:516-21.

34 Taggart D, Westaby S. Neurological and cognitive disorders after coronary artery bypass grafting. Curr Opin Cardiol 2001;16:271-6.

35 Moody D, Bell M, Challa V, Johnston W, Prough D. Brain microemboli during cardiac surgery or aortography. Am Neurol 1990;28:477-96.

36 Lee J, Lee S, Tsushima W, Yamauchi H, Lau W, Popper J, et al. Benefits of off-pump bypass on neurologic and clinical morbidity: a prospective randomised trial. Ann Thorac Surg 2003;76:18-26.

37 Russell D, Bornstein N. Methods of detecting potential causes of vascular cognitive impairment after coronary artery bypass grafting. J Neurol Sci 2005;229-30:69-73.

38 Grocott H, Mackensen G, Grigore A, Mathew J, Reves J, Phillips-Bute B, et al. Postoperative hyperthermia is associated with cognitive dysfunction after coronary artery bypass graft surgery. Stroke 2002;33:537-41.

39 Stanley T, Mackensen G, Grocott H, White W, Blumenthal J, Laskowitz D, et al. The impact of postoperative atrial fibrillation on neurocognitive outcome after coronary artery bypass graft surgery. Anesth Analg 2002;94:290-5.

40 Grigore A, Mathew J, Grocott H, Reves J, Blumenthal J, White W, et al. Prospective randomised trial of normothermic versus hypothermic cardiopulmonary bypass on cognitive function after coronary artery bypass graft surgery. Anethesiology 2001;95:1110-9

41 Grigore A, Grocott H, Mathew J, Phillips-Bute B, Stanley T, Butler A, et al. The rewarming rate and increased peak temperature after neurocognitive outcome after cardiac surgery. Anesth Analg 2002;94:4-10.

42 Murkin J, Martzke J, Buchan A, Bentley C, Wong C. A randomised study of the influence of perfusion technique and $\mathrm{pH}$ management strategy in 316 patients undergoing coronary artery bypass surgery: neurologic and cognitive outcomes. J Thorac Cardiovasc Surg 1995;110:349-62.

43 Newman M, Kirchner J, Phillips-Bute B, Gaver V, Grocott H, Jones R, et al. Longitudinal assessment of neurocognitive function after coronary artery bypass surgery. $N \mathrm{Engl}$ Med 2001;344:395-402.

44 Van Dijk D, Jansen E, Hijman R, Nierich A, Diephuis J, Moons K, et al. Cognitive outcome after off-pump and on-pump coronary artery bypass graft surgery: a randomised trial. JAMA 2002;287:1405-12.

45 Van Dijk D, Moons K, Keizer A, Jansen E, Hijman R, Diephuis J, et al. Association between early and three month cognitive outcome after off-pump and on-pump coronary bypass surgery. Heart 2004;90:431-4.

46 Diegeler A, Hirsch R, Schneider F, Schilling L, Falk V, Rauch T, et al. Neurocognitive outcome in off-pump versus conventional coronary bypass operation. Ann Thorac Surg 2000;69:1162-6

47 Collie A, Darby D, Falleti M, Silbert B, Maruff P. Determining the extent of cognitive change after coronary surgery: a review of statistical procedures. Ann Thorac Surg 2002;73:2005-11.

48 Browne S, Halligan P, Wade D, Taggart D. Cognitive performance after cardiac operation: implications of regression toward the mean. J Thorac Cardiovasc Surg 1999;117:481-5

49 Wahrborg P, Booth JE, Clayton T, Nugara F, Pepper J, Weintraub WS, et al. Neuropsychological outcome after percutaneous coronary intervention or coronary artery bypass grafting. Results from the stent or surgery (SoS) trial. Circulation 2004;110:3411-7.

50 Bucher H, Guyatt G, Cook D, Holbrook A, McAlister A. Users' guide to the medical literature: a manual for evidence-based clinical practice. Chicago: AMA Press, 2002:393-413.

51 Snappin S. Noninferiority trials [commentary]. Curr Control Trials Cardiovasc Med 2000;1:19-21.

(Accepted 28 March 2006)

doi $10.1136 /$ bmj.38852.479907.7C

National Heart and Lung Institute, Imperial College of Science, Technology, and Medicine, Harefield Hospital, Middlesex UB9 6JH

Sharif Al-Ruzzeh specialist registrar in cardiothoracic surgery

Shane George consultant anaesthetist

Mahmoud Bustami consultant cardiologist

Jo Wray clinical psychologist

Charles Ilsley consultant cardiologist

Thanos Athanasiou consultant cardiothoracic surgeon

Mohamed Amrani consultant cardiothoracic and transplant surgeon

Correspondence to: M Amrani mohamedamrani@hotmail.co.uk 